\title{
Effect of Estrogen Replacement Therapy on Hepatic Triglyceride Lipase, Lipoprotein Lipase and Lipids Including Apolipoprotein E in Climacteric and Elderly Women
}

\author{
MAMORU URABE, TAKARA YAMAMOTO, TOMOHIRO KASHIWAGI, \\ TOMOHARU OKUBO, HIROSHI TSUCHIYA, KOICHI IWASA, NORIKO KIKUCHI, \\ KaZUAKI YOKOTA, KeNICHI HOSOKAWA, AND Hideo HONJO \\ Department of Obstetrics and Gynecology, Kyoto Prefectural University of Medicine, Kyoto 602, Japan
}

\begin{abstract}
Estrogen provides beneficial effects on hyperlipidemia in climacteric and elderly women. In this study of 68 women ( 37 to 67 years old), hepatic triglyceride lipase (HTGL), lipoprotein lipase (LpL) serum lipids and apolipoproteins were analyzed to investigate the effects of estrogen replacement therapy (ERT). After menopause, LpL, total choresterol, low-density lipoprotein (LDL)-cholesterol, and apolipoprotein B increased. But ERT suppressed total cholesterol, LDL-cholesterol, apolipoprotein B, and especially apolipoprotein $E$ in menopausal women. The mechanism was thought that ERT significantly suppressed HTGL, but LpL was not affected. Estrogen also increases hepatic LDL receptors and accelerates transfer of serum LDL-C (and TC). It was said that HTGL accelerates conversion of intermediate-density lipoprotein (IDL) to LDL. The suppression of HTGL by the ERT may decrease conversion of IDL to LDL and lower LDL-C (and TC). These estrogen's beneficial effects on lipids, may prevent the atherosclerosis. In addition, apolipoprotein $\mathrm{E}$ increases senile plaques in senile dementiaAlzheimer's type. The decrease in apolipoprotein E with ERT may be related to cognitive functions of elderly women.
\end{abstract}

Key words: Hepatic triglyceride lipase, Lipoprotein lipase, lipids, Hormone replacement therapy, Apolipoprotein E

(Endocrine Journal 43: 737-742, 1996)

HYPERLIPIDEMIA has become prominent in climacteric and elderly women [1]. Hypercholesterolemia ( $\geqq 220 \mathrm{mg} / \mathrm{d} l$ ) is seen in $46.2 \%$ of Japanese women in their $50 \mathrm{~s}$ and $52.6 \%$ in their $60 \mathrm{~s}$, that is after menopause when endogenous estrogens decrease. In fact, the leading cause of death in women in 1993 was heart disease (25\%), and the third most common was cerebrovascular disease

Received: July 26, 1996

Accepted: August 2, 1996

Correspondence to: Dr. Mamoru URABE, Department of Obstetrics and Gynecology, Kyoto Prefectural University of Medicine, Kawaramachi, Hirokoji, Kamigyo-ku, Kyoto 602, Japan
(17\%) [2]. Both conditions are closely associated with hyperlipidemia. Estrogen provides beneficial effects on hyperlipidemia after menopause [3]. Estrogen replacement therapy (ERT) has become common in Japanese women [4]. Recently, $\varepsilon 4$ allele of apolipoprotein $\mathrm{E}$ (apo E) was reported to be a risk factor for late-onset senile dementia-Alzheimer's type (SDAT) [5]. Apo E accelerates precipitation of $\beta$-protein in senile plaques in SDAT $[6,7]$. In this study, post heparin plasma lipases, namely hepatic triglyceride lipase (HTGL) and lipoprotein lipase $(\mathrm{LpL})$, various lipids including apo $\mathrm{E}$, and estrogen were analyzed to clarify the roles of these lipases under ERT. The effects of ERT on apolipoproteins were also investigated. 


\section{Method}

Sixty-eight climacteric and elderly women (37 to 67 years old) without complications were recruited from among our outpatients. The aim of this study was explained and informed consent was obtained from these women. They were divided into 11 groups, (a)-(k), as shown in Table 1. ERT was performed as follows: day 0 to $21,0.625$ to $1.25 \mathrm{mg} /$ day conjugated estrogen (CE); day 22 to 28 , no hormone treatment. This cycle was repeated. In ERT (with P), $2.5 \mathrm{mg} /$ day medroxyprogesterone acetate (MPA) was also given on days 11 to 21 of ERT. ERT(+) means that at least one cycle or more of ERT was given. ERT(-) means that no ERT was given for at least 2 months. Just finished ERT means that it was within 6 days after finished ERT.

Serum samples were obtained between $0900 \mathrm{~h}$ and $1400 \mathrm{~h}$ at our outpatient department in the fasting state. These serum samples were used to determine plasma levels of total cholesterol (TC, $\mathrm{mg} / \mathrm{d} l$ ), high density lipoprotein-cholesterol (HDL$\mathrm{C}, \mathrm{mg} / \mathrm{d} l)$, triglyceride (TG, $\mathrm{mg} / \mathrm{d} l$ ), apo A-1 (mg/ $\mathrm{d} l)$, apo $\mathrm{B}(\mathrm{mg} / \mathrm{d} l)$, apo $\mathrm{E}(\mathrm{mg} / \mathrm{d} l)$, estradiol- $17 \beta$ $\left(\mathrm{E}_{2}, \mathrm{pg} / \mathrm{ml}\right)$, lipid peroxides ( $\left.\mathrm{LP}, \mathrm{nM} / \mathrm{ml}\right)$ and post heparin plasma lipases (HTGL, $\mu \mathrm{M} / \mathrm{ml} / \mathrm{min}$ and $\mathrm{LpL}, \mathrm{ng} / \mathrm{ml}$ ). Into the antecubital vein on one side, heparin $(30 \mathrm{U} / \mathrm{Kg}$, in $10 \mathrm{ml}$ saline) was administered. Ten min later a plasma sample was obtained from the other antecubital vein. This sample was used to measure HTGL and LpL. These data on HTGL and LpL were used after $10 \mathrm{~min}$ in this study.

The TC level was measured by an enzymatic method and HDL-C was measured by a phospho- tungstate $/ \mathrm{Mg}^{2+}$ precipitation procedure [8]. The TG level was measured by an enzymatic method. The LDL-C level was calculated with Friedewald's equation [9]. Levels of Apo A-1, B, and E were measured by immunoturbidimetry [10]. $E_{2}$ was measured by a radio immunoassay. Lipid peroxides were measured with a methylen blue derivative [11].

The HTGL level was measured by an immunochemical method [12], and LpL was measured by an enzyme immunoassay [13].

Statistical analysis of results was performed by Student's $t$-test, unpaired, and simple regression.

\section{Results}

Comparison of the (a) premenopausal and ERT( - ) group with the (c) postmenopausal and ERT (-) group

In women who also did not receive ERT [(a) premenopausal group, 16 women and (c) postmenopausal group, 19 women], neither HTGL nor $\mathrm{LpL}$ changed with age. On the other hand, LpL $(P<0.05)$, TC $(P=0.001)$ and LDL-C $(P<0.005)$ were higher in the (c) postmenopausal and ERT $(-)$ group than in the (a) premenopausal and ERT (-) group (Table 2). The mean level of HTGL was relatively higher in the (c) postmenopausal and ERT (-) group than in the (a) premenopausal and ERT (-) group (without statistical difference). The mean level of Apo E was higher in the (c) postmenopausal and ERT (-) group than in the (a) premenopausal and ERT (-) group. Serum $\mathrm{E}_{2}$ showed a very low level in the (c) postmenopausal and ERT $(-)$ group $(P<0.0005)$.

Table 1. Subjects

\begin{tabular}{l} 
Premenopausal women: $20\left[\begin{array}{l}\text { (a) ERT (-): } 16 \\
\text { (b) ERT (+): } 4\end{array}\left[\begin{array}{l}\text { (f) ERT (without P): } 1 \\
\text { (g) ERT (with P): } 3\end{array}\right.\right.$ \\
Postmenopausal women: $48\left[\begin{array}{l}\text { (c) ERT (-): } 19 \\
\text { (d) ERT (+): } 29\end{array}\right.$ \\
$\begin{array}{l}\text { (h) ERT (without P): } 14 \\
\text { (i) ERT (with P): } 15\end{array}$ \\
(e) Just finished ERT: $12\left[\begin{array}{l}\text { (j) ERT (without P): } 5 \\
\text { (k) ERT (with P): } 7\end{array}\right.$ \\
\hline
\end{tabular}

ERT, estrogen replacement therapy, ERT (-) means no ERT within 2 months. Just finished ERT means that it was within 6 days after finished ERT. P, medroxyprogesterone acetate. 
Table 2. Comparisons of postheparin plasma lipases and lipids etc

\begin{tabular}{llccccc}
\hline & & $\mathrm{a}$ & $\mathrm{c}$ & $\mathrm{e}$ & $\mathrm{a}$ vs. c & $\mathrm{c}$ vs. e \\
\hline Age & year & $45.6 \pm 4.79$ & $54.8 \pm 6.95$ & $52.2 \pm 3.90$ & $=0.0001$ & $\mathrm{~ns}$ \\
$\mathrm{HTGL}$ & $\mu \mathrm{M} / \mathrm{ml} / \mathrm{min}$ & $0.182 \pm 0.064$ & $0.198 \pm 0.064$ & $0.145 \pm 0.037$ & $\mathrm{~ns}$ & $<0.05$ \\
$\mathrm{LpL}$ & $\mathrm{ng} / \mathrm{ml}$ & $225 \pm 53.5$ & $267 \pm 58.5$ & $281 \pm 29.0$ & $<0.05$ & $\mathrm{~ns}$ \\
$\mathrm{TC}$ & $\mathrm{mg} / \mathrm{d} l$ & $189 \pm 30.6$ & $232 \pm 37.2$ & $190 \pm 24.6$ & $=0.001$ & $<0.005$ \\
$\mathrm{LDL}-\mathrm{C}$ & $\mathrm{mg} / \mathrm{d} l$ & $110 \pm 23.9$ & $145 \pm 38.2$ & $97.1 \pm 27.1$ & $<0.005$ & $<0.005$ \\
$\mathrm{HDL}-\mathrm{C}$ & $\mathrm{mg} / \mathrm{d} l$ & $58.6 \pm 13.4$ & $63.1 \pm 15.3$ & $69.4 \pm 12.5$ & $\mathrm{~ns}$ & $\mathrm{~ns}$ \\
$\mathrm{TG}$ & $\mathrm{mg} / \mathrm{d} l$ & $103 \pm 67.0$ & $125 \pm 59.1$ & $118 \pm 35.3$ & $\mathrm{~ns}$ & $\mathrm{~ns}$ \\
Apo A-1 & $\mathrm{mg} / \mathrm{d} l$ & $125 \pm 20.9$ & $131 \pm 19.1$ & $151 \pm 25.8$ & $\mathrm{~ns}$ & $<0.05$ \\
Apo B & $\mathrm{mg} / \mathrm{d} l$ & $92.2 \pm 26.7$ & $114 \pm 34.4$ & $87.1 \pm 12.0$ & $<0.1$ & $<0.05$ \\
Apo E & $\mathrm{mg} / \mathrm{d} l$ & $4.48 \pm 1.43$ & $4.87 \pm 1.63$ & $3.41 \pm 0.748$ & $\mathrm{~ns}$ & $<0.01$ \\
$\mathrm{LP}$ & $\mathrm{nM} / \mathrm{ml}$ & $4.59 \pm 1.14$ & $4.18 \pm 0.859$ & $3.64 \pm 1.26$ & $\mathrm{~ns}$ & $\mathrm{~ns}$ \\
Insulin & $\mu \mathrm{U} / \mathrm{m} l$ & $6.44 \pm 2.87$ & $9.09 \pm 16.1$ & $3.56 \pm 1.68$ & $\mathrm{~ns}$ & $\mathrm{~ns}$ \\
$\mathrm{E}_{2}$ & $\mathrm{pg} / \mathrm{m} l$ & $168 \pm 163$ & $14.2 \pm 9.42$ & $86.3 \pm 81.1$ & $<0.0005$ & $<0.001$ \\
\hline
\end{tabular}

a, premenopausal and ERT (-) group (16 women); c, postmenopausal and ERT (-) group (19 women); e, postmenopausal and just finished ERT group (12 women).

Comparison of the (c) postmenopausal and ERT (-) group with the (e) postmenopausal and recent ERT(+) group

The ages in the (c) postmenopausal and ERT(-) group (19 women) and the (e) postmenopausal and recent ERT (+) group (12 women) were not significantly different. The HTGL level was significantly suppressed in the (e) postmenopausal and recent ERT(+) group, compared with that in the (c) postmenopausal and ERT $(-)$ group $(P<0.05$, Table 2$)$. The LpL level showed no difference. Serum $E_{2}$ and HTGL levels showed a weak inverse correlation $(\mathrm{r}=-0.354, P<0.1)$. Serum $\mathrm{E}_{2}$ and $\mathrm{LpL}$ levels showed no correlation.

The TC $(P<0.005)$, LDL-C $(P<0.005)$, Apo B $(P<0.05)$, and especially Apo $\mathrm{E}(P<0.01$, Table 2$)$ levels were significantly suppressed in the (e) postmenopausal and recent ERT $(+)$ group, compared with those in the (c) postmenopausal and ERT $(-)$ group. In contrast, serum $\mathrm{E}_{2}(P<0.001)$ and apo A$1 \quad(P<0.05)$ levels were higher in the (e) postmenopausal and ERT $(-)$ group. The LP and insulin levels were similar in the above groups.

The (e) postmenopausal and recent ERT (+) group (12 women) was composed of the (j) ERT (= $-\mathrm{P})$ group (=without progestogen, 5 women) and (k) ERT $(=+\mathrm{P})$ group (=combination with progestogen, MPA, 7 women). Between the $(j)$ and $(k)$ groups, all parameters, including HTGL, LpL, lip- ids and so on showed no effect on post heparin plasma lipases and lipid levels.

\section{HTGL and lipids}

In whole samples, HTGL showed direct correlations with TC $(r=0.436, P<0.0005)$, LDL-C $(r=0.460$, $P<0.0005$, Fig. 1$)$ and apo B $(r=0.446, P=0.0005)$ levels.

The apo E level was $4.80 \pm 1.49 \mathrm{mg} / \mathrm{d} l$ in cases with $<20 \mathrm{pg} / \mathrm{ml}$ of serum $E_{2}$ and higher $(P<0.005)$ than that $(3.75 \pm 1.13 \mathrm{pg} / \mathrm{ml})$ in cases with $\geqq 20$ $\mathrm{pg} / \mathrm{ml}$ of serum $\mathrm{E}_{2}$.

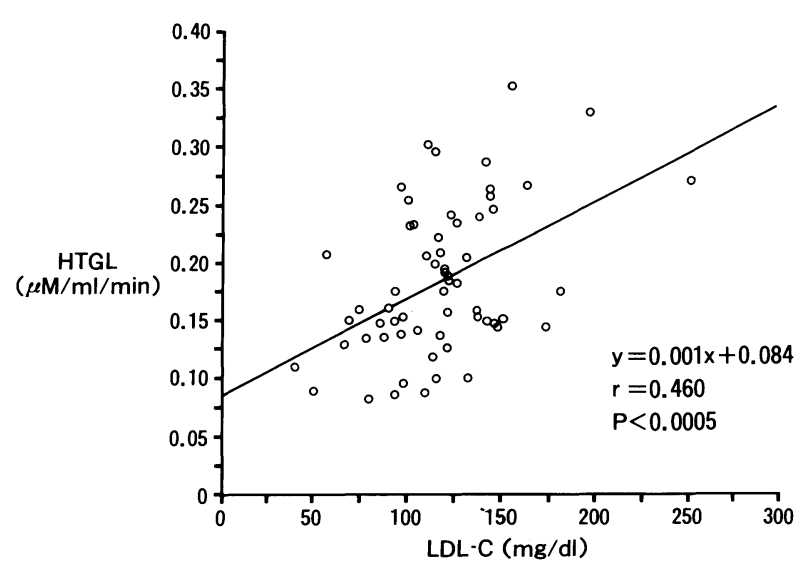

Fig. 1. HTGL and LDL-C in all samples. 


\section{Discussion}

Applebaum-Bowden et al. [14] administered ethinylestradiol $(1 \mu \mathrm{g} / \mathrm{kg} /$ day) to six postmenopausal women and produced a remarkable decrease in HTGL after just 4 days. Colvin et al. [15] administered $E_{2}$ in a stepwise manner ( 0.5 to $20 \mathrm{mg}$ /day) to six postmenopausal women and showed that HTGL activity response was inversely correlated with the estrogen dose. Basdevant et al. [16] found a decrease in HTGL during oral $E_{2}$ treatment. In the present study, ERT suppressed HTGL but not LpL. Tikkanen et al. [17] administered estradiol valerate ( $2 \mathrm{mg} /$ day for 3 months) to six postmenopausal women and produced suppression of HTGL but no suppression of LpL. Suppression of LpL could be seen only after high levels of estrogens, as during the third trimester of pregnancy [18], pancreatitis in pregnant women with hypertriglyceridemia [19], and hypertriglyceridemia with a high dose of estrogen to elderly women [20]. HTGL accelerates conversion of HDL2-C to HDL3-C and induces uptake of HDL by the liver [21]. ERT increases HDL-C levels in postmenopausal women [3]. The suppression of HTGL may increase serum HDL-C. Serum apo-A-1, which is the main component of HDL, tended to increase with serum $E_{2}$ [4]. In the present study, apo A-1 was higher in the ERT group. Intestinal and/or hepatic production of apo A-1 may be stimulated by estrogen, and, HDL and HDL-C may increase.

In our previous study [3], ERT strongly suppressed LDL-C after menopause. The present study also showed remarkable suppression of LDL$C$ and TC. Estrogen increases hepatic LDL receptors and accelerates transfer of serum LDL-C (and TC). On the other hand, HTGL accelerates conversion of intermediate-density lipoprotein (IDL) to LDL [22]. In the present study, HTGL decreased along with TC, LDL-C and apo B. The suppression of HTGL by the ERT may decrease conversion of IDL to LDL and lower LDL-C (and TC).

Estrogens have other beneficial effects on the vascular system [4]. Estrogens, especially, estradiol 17-sulfate $\left(E_{2}-17-S\right)$ and its catecholized form, $\mathrm{E}_{2}-17-\mathrm{S}$ (2-OH $\left.\mathrm{E}_{2}-17-\mathrm{S}, 4-\mathrm{OH} \mathrm{E}_{2}-17-\mathrm{S}\right)$, strongly suppress lipid peroxidation [23]. These estrogens may protect human arterial endothelial cells from oxidative stress, and may inhibit oxidation (oxidizing degeneration) of LDL-C and suppress atherosclerosis of the vascular endothelium [24]. The third beneficial effect, ERT may become more widely applied. Today, combination with progestogen is recommended to protect against uterine endometrial cancer and other conditions [25]. On the other hand, the effect of the combination of progestogen with ERT on coronary heart disease is still unclear. In the present study, which was not conclusive because of the small number of cases, no difference was found in the post heparin plasma lipases and lipids with and without progestogens. Further large-scale studies on the effects of combined ERT on cardiovascular risk are necessary.

It is possible that estrogen has ameliorative effects on SDAT senile dementia-Alzheimer's type [26]. Senile plaques in SDAT are made of amyloid. The main component of amyloid is $\beta$-protein. Apo $\mathrm{E}$ accelerates precipitation of $\beta$-protein $[6,7]$. The $\varepsilon 4$ allele of apo E may be a risk factor for lateonset SDAT [5]. In the present study, Apo E was higher in cases with $<20 \mathrm{pg} / \mathrm{ml}$ of serum $E_{2}$. Apo E was noticeably suppressed by ERT in postmenopausal women. Our other conjugated estrogen therapy suppressed apo E significantly after 4 weeks (unpublished data). With ethinylestradiol administration [14] apo E decreased significantly.

Finally, the effect of ERT on lipid metabolism needs to be further investigated, but ERT may be useful in the management of postmenopausal women with hyperlipidemia, and also in the prevention of cardiovascular disease. ERT may improve the quality of life of postmenopausal women.

\section{Acknowledgements}

This study was supported in part by a Research Grant for Intractable Diseases (Primary hyperlipidemia), from the Ministry of Health and Welfare, Research Institute for Neurological Diseases and Geriatrics and Works of Scientific Research and Technical Development, Public Health Department of Kyoto Prefectural Government. 


\section{References}

1. Ministry of Health and Welfare (KOSEISHO) (1993) Summary of National survey of circulatory disorders (1990). Japan, Tokyo, pp. 1-23, (In English), pp. 1-5, Figs. and Tables 1-17 (In Japanese).

2. Ministry of Health and Welfare (KOSEISHO) (1994) Abridged Life Table, 1993. Japan, Tokyo, pp. 1-12 (In Japanese).

3. Honjo H, Tanaka K, Urabe M, Naitoh K, Ogino $Y$, Yamamoto T, Okada H (1992) Menopause and hyperlipidemia: Pravastatin lowers lipid levels without decreasing endogenous estrogens. Clin Ther 14: 699-707.

4. Honjo H (1993) Manual for Climacteric and Elder Women's Clinic-An Invitation to Queen's Corner. Kyoto, Kinpodo (In Japanese).

5. Anwar N, Lovestone S, Cheetham ME, Levy R, Powell JF (1993) Apolipoprotein E- $\varepsilon 4$ allele and Alzheimer's disease. Lancet 342: 1308-1309.

6. Peacock ML, Fink JK (1994) Apo E $\varepsilon 4$ allelic association with Alzheimer's disease: Independent confirmation using denaturing gradient gel electrophoresis. Neurology 44: 339-341.

7. Hardy J (1994) Apo E amyloid and Alzheimer's disease. Science 263: 454-455.

8. Bullock DG, Carter TJN, Hughes SV (1980) Applicability of various quality-control sera to assay of high-density lipoprotein cholesterol. Clin Chem 26: 7, 903-907.

9. Friendewald WT, Levy RJ, Fredrickson DS (1972) Estimation of the concentration of low density lipoproteins in plasma, without use of preparative ultracentrifuge. Clin Chem 18: 499-502.

10. Itakura K, Matsudate T, Sakurai T, Hashimoto S, Ito K, Kanno H, Hirata M, Nakamura K (1986) Single radial immunodiffusion of serum apolipoproteins C-II, C-III and E-pretreatment of samples with surfactant. Clin Chim Acta 161: 275282.

11. Ohishi N, Ohkawa H, Miike A, Tatano T, Yagi K (1985) A new assay method for lipid peroxides using a methylene blue derivative. Biochem Intern 10: 205-211.

12. Huttunen JK, Ehnholm C, Kinnunen PKJ, Nikkla EA (1975) An immunochemical method for the selective measurement of two triglyceride lipases in human postheparin plasma. Clin Chem Acta 63: 335347.

13. Ikeda $Y$, Takagi A, Ohkaru $Y$, Nogi K, Iwanaga T, Kurooka S, Yamamoto A (1990) A sandwich-enzyme immunoassay for the quantification of lipoprotein lipase and hepatic triglyceride lipase in human postheparin plasma using monoclonal anti- bodies to the corresponding enzymes. J Lipid Res 31: 1911-1924.

14. Applebaum-Bowden D, Mclean P, Steinments A, Fontana D, Mathys C, Warnick GR, Cheung M, Alberts JJ, Hazzard WR (1989) Lipoprotein, apolipoprotein, and lipolytic enzyme changes following estrogen administration in postmenopausal women. J Lipid Res 30: 1895-1906.

15. Colvin PL Jr, Auerbach BJ, Case LD, Hazzard WR, Applebaum-Bowden D (1991) A close-response relationship between sex hormone-induced change in hepatic triglyceride lipase and high-density lipoprotein cholesterol in postmenopausal women. Metabolism 40: 1052-1056.

16. Basdevant A, Blache D, de Lignieres B, Ponsin G, Simon P, Guy-Grand B (1991) Hepatic lipase activity during oral and parenteral $17 \beta$-estradiol replacement therapy: High-density lipoprotein increase may not be antiatherogenic. Fertil Steril 55: 1112-1117.

17. Tikkanen MJ, Kuusi T, Nikkilä EA, Sane T (1985) Very low density lipoprotein triglyceride kinetics during hepatic lipase suppression by estrogen: Studies on the physiological role of hepatic endothelial lipase. FEBS Lett 181: 160-164.

18. Herrera E, Lasunción MA, Gomez-Coronado D, Aranda P, López-Luna P, Maier I (1988) Role of lipoprotein lipase activity on lipoprotein metabolism and the fate of circulating triglycerides in pregnancy. Am J Obstet Gynecol 158: 1575-1583.

19. Otabe M. Matsuoka N, Sasaki N, Shirai K, Saito $Y$, Yoshida S, Hayashi H (1986) Effect of premarin on lipoprotein lipase activity. Arteriosclerosis 13: 13971401 (In Japanese).

20. Honjo H, Ogino $Y$, Naitoh K, Urabe M, Kitawaki J, Yasuda J, Yamamoto T, Ishihara S, Okada $\mathrm{H}$, Yonezawa T, Hayashi K, Nambara T (1989) In vivo effects by estrone sulfate on the central nervous system-senile dementia (Alzheimer's type). J Steroid Biochem 34: 521-525.

21. Carlson LA, Holmquist L, Nilsson EP (1986) Deficiency of hepatic lipase activity in post-heparin plasma in familial hyper- $\alpha$-triglyceridemia. Acta Med Scand 219: 435-447.

22. Felts JM, Itakura H, Crane RT (1975) The mechanism of assimilation of constituents of chylomicrons, very low density lipoproteins and remnants-A new theory. Biochem Biophys Res Commun 66: 14671475.

23. Honjo H, Tanaka K, Yasuda J, Ohno Y, Kitawaki J, Naitoh K, Ogino Y, Yamamoto T, Okada H, Watanabe K, Yoshizawa I (1992) Serum estradiol 
17-sulfate and lipid peroxides in late pregnancy. Acta Endocrinol (Copenh) 126: 303-307.

24. Rosano GMC, Sarrel PM, Poole-Wilson PA, Collins $P$ (1993) Beneficial effect of oestrogen on exerciseinduced myocardial ischemia in women with coronary artery disease. Lancet 342: 133-136.

25. Grady D, Rubin SM, Petitti DB, Fox CS, Black D, Etting B, Ernster VL, Cummings SR (1992) Hormone therapy to prevent disease and prolong life in postmenopausal women. Ann Inter Med 117: 1016-1037.

26. Honjo $\mathrm{H}$, Ogino $\mathrm{Y}$, Tanaka $\mathrm{K}$, Urabe $\mathrm{M}$, Kashiwagi T, Ishihara S, Okada $H$, Araki K, Fushiki S, Nakajima K, Hayashi K, Hayashi M, Sasaki T (1993) An effect of conjugated estrogen to congnitive impairment in women with senile dementiaAlzheimer's type: A placebo-controlled double blind study. J Jpn Menopause Soc 1: 167-171. 